\title{
Parental influence and HE decision making: The continuing power of local culture.
}

\author{
Wayne Bailey: w.bailey@hud.ac.uk \\ School of Education and Professional Development, University of Huddersfield, \\ Huddersfield, England
}

\begin{abstract}
This case study illustrates why a group of young adults from a working-class community in the UK choose not to participate in HE despite having the necessary qualifications. It highlights the impact that parents have on HE participation decisions, and the network of social connections participants are able to mobilise from their parents. It shows how objective social structures such as the family can influence values, cultural rules and decision making, both directly and indirectly. It was found that, although parents were initially supportive of Higher Education (HE) participation, they appeared to quickly exhibit collective expectations and socially inculcated beliefs pertaining to employment and the need to make money. The socialisation that took place in the family made participants believe that non-participation was best and that employment was the right thing to do. This case study utilises the work of Bourdieu, Coleman and Putnam, with findings being drawn from a set of semi-structured interviews with 33 young adults. This article enhances our understanding of the influence of parents on HE decision making because it provides details about the way that parental influence works both directly and indirectly.
\end{abstract}

Keywords: cultural rules, parents, social capital, decision making

\section{Introduction and background}

This article uses a case study approach to investigate why a group of young adults, from a working-class community in the UK, choose not to participate in HE. It focuses on the impact that parents have on HE participation decisions, and the 
network of social connections participants are able to mobilise due to their parents. In doing so, it considers the degree to which social capital, which is embedded within networks, impacts on how individuals participate in and are included within society and how this can influence HE decision making (Putnam, 2000). Within this article, social capital is defined as “... connections among individuals' social networks and the norms of reciprocity and trustworthiness that arise from them" (ibid, p.19).

The literature recognises the important part parents play when young people decide about HE participation (Ball, Reay and David, 2002; Brooks, 2003, Hegna and Smette, 2017), with up to $90 \%$ of people talking to their parents about HE participation, and rating parents as a source of information they would listen to most when deciding about HE (Dodgson, 2004).

This case study takes place in Northtown which under performs on a number of educational and social indicators that reflect high levels of social deprivation. Northtown is in the top $20 \%$ of the most deprived areas in the UK with many people having low-level or no qualifications with a small number of young people staying on in education (Department for Communities and Local Government, 2015). This suggests that Northtown provides an interesting study for exploring the influence of parents on HE participation decisions.

In order to investigate this further I review the existing research on both the influence of parents and the role of broader social networks on decisions to participate or not in $\mathrm{HE}$, after briefly considering wider influences on $\mathrm{HE}$ participation decisions.

\section{Influences on non-participation decisions}


Research suggests a number of reasons for non-participation in HE including the influence of social class and cultural issues with those young people from relatively disadvantaged areas being shown to be less likely to participate (Callender and Mason, 2017) as well as debt aversion (Esson and Ertl, 2016; Jones, 2016; Bailey, 2018; Evans and Donelly 2019). Other research on the aspirations of non-participants, and how these affect young peoples' desire to participate in HE has shown that some individuals and communities do not see the value of HE participation (Burke, 2012). Finally, studies highlight the important role of schools suggesting that they appear to mediate HE choices due to how they send out messages about post-school and HE options (Donnelly 2015).

There seems to be a persuasive view that the choices people make about participation in HE is an immensely complex and messy process (Reay, 2001) and although this paper acknowledges a multitude of influences on HE participation decisions, it concentrates on the influence that parents have on such decisions.

\section{The influence of parents on HE participation decisions in the UK}

Hegna and Smette (2017) highlight the positive and supportive role of parents and suggest that they are a strong influence on the educational decision making of young people. However, the educational and occupational background of parents, in conjunction with their socio-economic status appears to influence and shape their educational expectations of their children (Koshey, Dockery and Seymour (2019).

Evidence suggests that a family's class position has a strong bearing on participation decisions (Brooks, 2003; Mangan, Hughes, Davies and Slack, 2010) and on how people understand the HE market (Ball et al., 2002). Several studies have found 
that many working-class parents support their children in whatever decisions they make regarding HE participation, although they may not be prepared to push them in a particular direction (Reay, 1998; Conner and Dewson, 2001).

Heaslip, Hewitt-Taylor, Alexander, Ellis-Hill and Cassia (2015), found that many working-class parents encouraged their children to attend university and, overall, had high aspirations for them. However, there seem to be underlying fears associated with family norms and values being abandoned (Thomas and Quinn, 2003), with some parents showing concerns about their children being separated from their family and community (Wilks and Wilson, 2012). Scanlan, Powell, Leahy, Jenkinson and Byrne (2019) suggest that parents value education as a means of gaining a 'good job' but that they are concerned about the financial implications of HE participation. Therefore, financial constraints associated with HE participation appear to lead to a renegotiation of aspirations (Baker 2019). Significantly, working-class parents who have not been to university are less able to advise their children as they have no family history of HE (Jones, 2016), with individuals from disadvantaged families being unable to draw on the vicarious experiences of parents (Foster and Higson, 2008).

\section{The Role of Social Networks}

Heath, Fuller and Johnston (2010) explored the ways in which HE decision making, or non-decision making, was influenced by social networks. Educational experiences within networks appeared to play a pivotal role in shaping the perceptions of other network members. Networks refer to extended groups of people that have similar interests; they interact with each other and remain in informal contact for mutual assistance or support. 
The degree to which social capital, which is embedded within networks, impacts on how individuals participate in and are included within society (Putnam, 2000) can influence HE decision making. Coleman and Putnam are widely accepted as making significant contributions to the way social capital is understood (Field, 2003). Each focuses on networks and how forms of advantage and disadvantage are transmitted.

Putnam (2000) suggests that various forms of social capital have an impact on how people can participate in the educational sphere. Bridging social capital refers to diffused and indirect types of linkage and reciprocation within, and between, groups. Bonding social capital suggests specific forms of reciprocation associated with homogenous groups. It refers to values of solidarity, support and mutual reinforcement. There are possibilities for social mobility that are afforded by access to particular forms of social capital, with bridging capital having the potential to facilitate social mobility, whereas bonding capital is seen to reproduce inequalities that were already in existence. Heath et al., (2010) suggest that access to bridging capital represented by prior parental experience of $\mathrm{HE}$ is particularly important and is a key determinant of whether younger generations are likely to participate in HE.

Influence on HE participation can be exerted within networks by those who have had a prior experience of HE. Their experiences appear to be critical in shaping other people's perceptions. There are, however, other forms of social capital that identify possibilities for families and networks to develop 'linking capital', which enables vertical connections between social groups occupying different power positions. This gives people the ability to access institutional resources such as $\mathrm{HE}$ 
(Thomas and Quinn, 2003). Therefore, educational decision-making is embedded within networks and is not an individualised process (Fuller and Heath, 2010).

Coleman (1990) proposes that the relationships between parents and children, and the norms within their social networks are particularly valuable, with social capital existing both within family itself, but also within the wider community. Coleman's definition of social capital offers pride of place to family and kinship. Common meanings that are accumulated over time reflect shared attachments amongst family members. They provide a sense of identity that facilitate common understandings and traditions that help to build a sense of local identity and solidity. Parents have been shown to place particular emphasis on shared values, ideas, beliefs and expected behaviours that have the potential to influence HE decision making (Brennen, 2005). Coleman (1994) views social capital as a resource because reciprocity is seen to go further than a particular individual does and involves wider networks where shared values and trust govern the relationships that are fostered.

Now that I have explored the literature, I show how my methodology enabled me to investigate parental influence on HE participation decisions.

\section{Methodology}

A case study approach was followed in order to examine particular subjects, themes and issues relating to HE participation decisions (Gray, 2014). Through this case, I provide description and analysis of a bounded unit within real-life situations and context (Merriam, 2009). Specifically, the 'unit of analysis' is a group of young adults, from a working-class community in the UK, who resided in low-income, quintile 1 
neighbourhoods ${ }^{1}$ that were in the top $20 \%$ of the Index of Multiple Deprivation (IMD) ${ }^{2}$, who had chosen not to participate in HE. I wanted to better understand the direct and indirect influence of parents on the groups' participation decisions. In particular, I wanted to answer the following research questions:

- In what ways have parents' influenced HE participation decisions directly?

- How, indirectly, were the participants able to mobilise the social networks of their parents.

Although there is a suggestion that case studies are one of the weaker methods of qualitative inquiry because it is difficult to make generalisations (Yin, 2014) this approach was appropriate because it enabled an in-depth study of the group to be undertaken. It provided 'exemplary knowledge 'which offered a particular representation of parental influences on participation decisions, to be understood in a specific context (Thomas, 2011). Through rich description, I was able to gain a better understanding of the participants' decision making by focusing on specific complexities and their uniqueness (Schram, 2006). Such in depth insights, although contextual, could potentially be transferred to similar situations (Merriam, 2009).

\footnotetext{
${ }^{1}$ POLAR classification shows, across five quintiles, how the possibilities of young people entering $\mathrm{HE}$ varies because of the area where they live. Each quintile represents $20 \%$ of UK young cohort, their classification groups areas from ' 1 ' (those wards with the lowest participation) to ' 5 ' (those wards with the highest participation) (Office for Students, 2019)

${ }^{2}$ The English Indices of Deprivation measure relative levels of deprivation in 32,844 small areas or neighbourhoods, called Lower-layer Super Output Areas, in England (Department of Communities and Local Government, 2015).
} 
There is some evidence to suggest that bias can be a challenge when using a case study approach, with researchers seeking information that confirms their beliefs, whilst glossing over information that contradicts their beliefs. To overcome this I have used the detailed insights of participants' verbatim testimony and key literature. I also make use of theoretical frameworks to justify key findings (Della Porta and Keating, 2008).

\section{Sample}

Purposive sampling was chosen, because this type of sampling fit the parameters of 'the unit of analysis'. I selected two institutions in Northtown that offered sixth form education because they had students who had chosen not to participate and who resided in low-income, quintile 1 neighbourhoods that were in the top $20 \%$ of the Index of Multiple Deprivation (IMD).

Town Sixth Form is part of a large tertiary college serving the town and surrounding areas, $80 \%$ of school leavers in the town attend the college. At Town Sixth Form, 628 students completed their academic level three qualifications. The sixth form identified 122 students who suggested they did not intend to participate in HE. I interviewed students who had chosen not to participate in $\mathrm{HE}$, with appropriate academic level three qualifications, who were prepared to be interviewed (13).

Village Academy is smaller than most secondary schools and the proportion of its students who are supported by the pupil premium ${ }^{3}$ or with a statement of special

\footnotetext{
${ }^{3}$ Pupil premium: a sum of money given to schools each year by the UK Government to improve the attainment of disadvantaged children (Department for Education, 2019) 
educational is well above average. At the Village Sixth Form 76 students completed their level 3 academic qualifications. I interviewed all those students that could attend university, but had chosen not to (20).

Thirty-three participants were interviewed, all were white, British (this was not a pre-set condition). All of the participants had the necessary qualifications to attend university, but had chosen not to (see table 1 for participant information). All participants suggested that they had discussed HE participation with staff at their respective institutions, 14 had attended university open days.

Table 1: Participant Information

\begin{tabular}{|c|c|c|c|}
\hline Institution & $\begin{array}{l}\text { Nos of } \\
\text { participants }\end{array}$ & Age & Gender \\
\hline Village Sixth Form & 20 & 18 (22 participants) & $\begin{array}{l}\text { Male } 8 \text { participants } \\
\text { Female } 12 \text { participants }\end{array}$ \\
\hline $\begin{array}{l}\text { Northtown Sixth } \\
\text { Form }\end{array}$ & 13 & $\begin{array}{l}18 \text { (10 participants) } \\
17 \text { (3 participants) }\end{array}$ & $\begin{array}{l}\text { Male } 7 \text { participants } \\
\text { Female } 6 \text { participants }\end{array}$ \\
\hline
\end{tabular}

\section{Methods, data collection, ethics and analysis}

Ponelis, (2015) suggests that interviews are an appropriate source of data collection for case study research, but that the process (es) used to collect and analyse data should be as explicit as possible (Shaw, 1999). Semi-structured interviews were utilised to gather information about the participants' key characteristics practices and attitudes. Specifically, participants' were asked about their choice not to participate and what, if anything, might have steered them towards HE. They were asked to think about the reasons behind their decision making. 
Using semi-structured interviews enabled the meaning of the central themes to become visible. It allowed participants to tell their stories in their own way, in their own words. This helped to gain a better understanding of the direct and indirect influence of parents on participation decisions, as they appeared in the context of their own frames of reference (Kvale, 2007).

However, in carrying out semi-structured interviews I was fully aware of the criticisms that have been levelled (Gray, 2014). For example, ambiguity can be a problem, with the possibility of participants giving contradictory statements during interviews, as well as them interpreting statements or questions that I asked, differently. It is worth noting, however, that the purpose of this research was not to "...end up with unequivocal and quantifiable meanings of the themes in focus" (Kvale, 2007, p.13). Whilst the interviews were semi-structured, there were some structured elements put in place to alleviate issues relating to ambiguities and contradictory statements. For example, questions were designed in such a way as to reflect the research questions, whilst taking into account the subject matter being researched and the age and education level of the participants (Kvale, 2007).

\section{Ethical issues}

Within this study, the specifics of individuals were not discussed. When reporting their viewpoints and opinions, each participant was allocated a number. Confidentiality and anonymity were assured; participants were treated with dignity, sensitively and fairly. Prior to the interview taking place, participants were informed that they had the right to withdraw from the research for no reason and at any time (British Education Research Association, 2018). 


\section{Analysis of data}

A case study should use theoretical frameworks to help provide explanation and analysis; however, in doing so, care must be taken to ensure that any chosen framework(s) are not lacking or ill suited. It is also important to ensure that any framework used be sufficiently specified and justified (Della Porta and Keating, 2008). With this in mind, in order to examine the direct and indirect influence of parents on HE participation decision making, this research is framed by some concepts developed by Bourdieu, Putnam and Coleman.

In utilising aspects of Bourdieu's corpus, this article takes account of the participants' subjective points of view concerning non-participation, whilst also giving attention to the circumstances which appeared to have shaped and moulded their decisions such as their parents, both directly and indirectly. Consequently, a number of Bourdieu's relational thinking tools are used to examine the decision making of the participants.

Bourdieu suggests that practice involves the formal naming of an activity that is undertaken that has structures, points of harmony, limits and meaning. I was looking for examples of common patterns of reaction that the participants shared when it came to their parents and what they viewed as being acceptable ways of doing things. I was also able to gain insight into the participants' predisposition towards certain courses of action, their values and strategies that were viewed as the 'natural way' of doing things - what Bourdieu refers to as habitus (Bourdieu, 1977).

I also use Bourdieu's ideas about the influence and importance of pedagogic actions which are carried out within the framework of social structures by peers, families and schools who inculcate meaning. It involves both the exclusion and 
inclusion of specific ideas (Bourdieu, 1973). The relative success of pedagogic action in different groups or classes relies on their pedagogic ethos, their disposition towards education and is a result of family education and a general recognition of the value of education (Bourdieu and Passeron, 1990). I sought to understand the pedagogic actions that were carried out within the participants' family structure and how these had influenced their participation decisions.

As the participants in this study are from working class, socially deprived areas of Northtown, I also use Coleman and Putnam's work on social capital to aid the analysis.

Coleman (1994) proposes that social capital can benefit those people living in poor marginalised communities, not just the powerful and as discussed above, Putnam (2000) distinguished between types of social capital. Collectively, both Putnam and Coleman emphasise the significance of trust and reciprocity which arises due to activities that both create but also contribute to social capital. They both suggest that this goes beyond any individual and involves wider networks. These networks are important, of value and can lead to collective norms and reciprocities (Coleman, 1994; Putnam, 2000). The work of Coleman and Putnam was utilised because this research highlights the importance of relationships and behaviours that were mutually beneficial to parents and participants respectively. Parents used their own social networks to help their children, to their mutual benefit. Parents both contributed to the participants' social capital, and helped them to begin to create their own.

A case study approach can be particularly productive in terms of the data that is gathered, therefore it is important that the data collected is analysed appropriately (Gray, 2014). Yin (2014) suggests an approach to analysis that takes account of 
highlighted research questions and any theoretical model(s) that have been used (see to enable any contrasting points of view and relationships to be highlighted.

As a general thematic approach was compatible with a case study methodology, it was utilised to analyse these data (Braun and Clarke, 2006) to enable relationships and contrasting variables within the case study to be investigated (Gray, 2014). As Braun and Clarke propose, (2006, p.85): “...thematic analysis...seeks to theorise the socio-cultural contexts and social conditions that enable the individual accounts that are provided". Following such an approach enabled data to be collected that aided the examination of the ways in which parents influence the participants' HE decision making, both directly and indirectly.

This study did not look for a predetermined list of specific themes, however, it did take account of a number of concepts (existing literature, Bourdieu, Coleman and Putnam) that might help to explain the non-participation of the participants and the influence that their parents had.

Specifically, the following phases were undertaken:

- Phase 1: familiarising yourself with the data

- Phase 2: generating initial codes

- Phase 3: searching for themes

- Phase 4: reviewing the themes

- Phase 5: defining and naming the themes and writing up the findings 
Once all 33 transcripts had been read through several times the initial ideas ${ }^{4}$ were outlined (phases 1 and 2 of the thematic analysis). From these initial codes, the emergent candidate themes were developed (phase 3). Throughout phase 3, when reviewing in phase 4 and when arriving at the final themes after phase 5, I highlighted quotations that best represented the themes. The quotations within the findings section were chosen because they best illustrated the participants' points of view as they related to the main themes that emerged from the data. The themes were:

- Expected behaviours; and cultural rules:

- A lack of knowledge and understanding.

\section{Findings}

Throughout this section, the quotes that are used were chosen because they were the most interesting and they best represented the participants' points of view pertaining to the indirect and direct influence of parents(s) on their HE participation decisions.

\section{Expected behaviours; and cultural rules}

All participants discussed the implications of HE participation with their parents. For the majority of participants it appeared to be an expected behaviour that they place value on the opinions of their parents and that their opinion had gravitas. One of the motivations behind non-participation was based on the expectation that participating

\footnotetext{
${ }^{4}$ Initial ideas: values, beliefs and norms; expected behaviour; importance of parents; importance of employment; relationships and connections are key; lack of HE knowledge and understanding; lack of confidence and abandoning the family.
} 
in HE could have a negative impact on their family due to potential financial and social implications of participation.

There was a sense of family solidarity that had been inculcated within the majority of the participants, and this seemed to influence their HE participation decision making. Important issues often appeared to be discussed in terms of how HE participation would impact on the whole family and not just the individual. The thoughts of participant 16 best illustrates this:

I asked my dad if he would really be happy if I went to university and he said so, but he said that he was right worried...and had I thought about getting a job... My mam really doesn't want me to go. She says I can go...and not to worry...cos we're all in it together.

The values of the young adults appeared to have been moulded by the parents and this, in turn, influenced the rules and behaviours which were deemed to be acceptable, particularly when it came to employment and leaving their families. As participants 9 and 27, suggest:

My mam says when everybody has got a degree there's no value to it...it shows more initiative if you've gone straight into employment...

They [parents] don't see the point of uni. They seem to think it will be easy for me to get a job...

The relationships that the participants have with their parents, in part, shaped their attitude to the prospect of HE participation, with alternatives to participation being discussed and prioritised by the majority of participants. Participants 18 and 29 illustrate this well:

...not many people nowadays will take the lowest jobs and work their way up. 
My mam thinks that's the best way to go.

I've talked to my mam and dad...they all seem to be saying that getting a job is best way ...l'll be making money then and won't owe folk.

In this study, the unwritten rules, values, behaviours and attitudes towards $\mathrm{HE}$ participation meant that the participants' family championed employment as a much more secure and viable alternative. For example:

...my dad's advised me that I don't really need to go [to university] and I could get into jobs quite easily and stay at home... (18)

... when they tell me to go, I'm not sure that I really believe them. My mam is always on about Tesco's and how I could get a good job there and work myself up...like she did (32).

For the parents, the most valuable skills and rewards were likely to be gained in the world of work. This was where important relationships and connections were forged and nurtured; where new networks of opportunity were formed. Parents used their own relationships and the networks to which they belonged, to mobilise their social capital on behalf of their children. Parents directed participants to close friends and family members who could potentially help them to gain employment. There was the suggestion that "...favours could be called in...my dad and his mates are always helping each other out" (Participant 5). Friends and family had become a resource; members had things in common and shared the same beliefs and values in terms of the importance of employment. There was also a suggestion from some that formal systems that other people might have to follow could even be overlooked. As participant 4 states: 
... when I said that I...didn't want to go to uni they were like, well we don't mind...as long as you get a full time job. My dad says a job will help me meet new people that will help me get on...he's put me in touch with a couple of fellas who he knows...I don't think I'll even need an interview, well that's what my dad says.

Implicit within the interviews was the respect participants had for their parents' opinion and how important their family members were to each other. Participants 16 and 21 illustrate this:

Family is important to me... I trust them. I know if I have any problems about anything that they will sort it...

I do what my mam and dad tell me and we all do what my nannan [Grandmother] says.

Whilst participant 21 was discussing the family dynamic in an ironic manner, participants appeared to have strong affective bonds with their parents. Whilst ultimately, the participants chose not to participate, there was an interesting discourse that evidenced initial support from parents. As participant 5 points out:

Well, my mam she'll just go 'oh get yourself gone' and that's all she'll say.

However, in all cases, participants inferred that they were not sure that they believed their parents, particularly when they probed further into their parents' opinions and this appeared to have influenced their decision making. For example:

I asked my dad if he would really be happy if I went to university and he said so, but he said that he was right worried...and had I thought about getting a job...he's got a mate, well a mate of my uncle who can help me get on with a right good firm (16). 
Once the participants said that they did not intend to participate in $\mathrm{HE}$, their parents did not attempt to change their minds, or encourage them to rethink their choice and they were quickly steered towards friends and/or family members who might help them to find employment. The participants believed that their parents would prefer them to get a job, earn money and to stay in their locality, rather than participate in HE. Utilising their parents' own formal and informal networks relationships, as highlighted above, was deemed best for the family.

\section{A lack of knowledge and understanding}

Whilst the participants discussed the importance of parents' opinions, significantly, none of the parents were able to tell their children much about participation in HE. As participant 30 points out:

My mum's told me some things about university that probably could've encouraged me to go. She says it will help me get a job, but she didn't tell me much...

Very few of the participants could articulate why they viewed parents as an appropriate source of information regarding HE. Participants were unclear about what they were hoping to glean from their parents and why it was so important that they

'...get their blessing' (participant 25). Participants 8 and 31 help to illustrate this point:

My mam and dad just left school and got a job so are not familiar with this [university].

Both my mam and dad want me to go to uni. I don't know why though; they don't seem to be able to tell me about it... 
Of the 33 participants interviewed, none of their parents had participated in $\mathrm{HE}$ and it was clear that parents were not good sources of information when it came to $\mathrm{HE}$, even though the participants wanted their opinions. This is in stark contrast to the parents understanding of employment opportunities that were available for the participants locally. However, they did not know the correct way of doing things when it came to giving their children the information they needed to make an informed decision about HE participation. Consequently the participants' lack of confidence stemmed from not getting advice and guidance about what to expect at university from their parents. For example:

I don't feel like I'm ready ... It would help if I could talk to my mam and dad about it...I need confidence to go out there and give it a go... (28)

In trying to explain their thoughts about parental attitudes a minority of participants referred to how HE participation might change them and how this impacted on their decision making, as they were worried about what their parents might think. Participants 12 and 29 illustrate this:

I was having a bit of a laugh with my dad about it and he told me, don't be getting all posh on me if you go to uni...I told him, not likely...I'm a Northtown lad.

I think my mam is worried that I might change and if I go to uni I might not live near her and my Dad...that really worries her...

In the eyes of some parents and participants there was a social impact because HE participation meant leaving the locality, living somewhere else and potentially abandoning their family. For example: 
My mam is dead worried about uni. She thinks I might leave Northtown and never come back...(13)

This also had an impact on the participants' thinking about where they might participate had they chosen to attend university. Participants 3 and 27 evidence the importance of locality in any potential participation decision.

I'd prefer to go local; I'd rather stay at home...this is my life, Northtown's my life...

....what's point of going...even if I did, I won't leave Northtown. We've always lived in the same place; it's where I belong. Like my granddad says...born in Northtown, die in Northtown...that suits me fine.

\section{Discussion: the direct and indirect influence of parents on HE participation decisions}

Whilst the majority of the participants' parents had gone through compulsory schooling, none of them had participated in HE. Consequently, whilst a minority seemed to have an idea of the potential profits engendered in the field of $\mathrm{HE}$, the majority of parents did not and instead steered the participants towards employment options. They appeared to be unfamiliar with the workings of HE and how it is organised, what Bourdieu (1984) called 'legitimate culture'. This is why the participants appeared to receive much less advice about HE participation from their parents than was required to make an informed decision about it (Crozier, Reay and Clayton 2010). This apparent lack of understanding of what HE involved seemingly influenced the participants' HE participation choices. Although the participants held their parents' opinions in very high regard and thought that they would support them should they wish to participate in $\mathrm{HE}$, they still chose not to participate. This seemed 
to be because, despite apparent initial support, the majority of participants believed that their parents did not really want them to participate and that they viewed nonparticipation as acceptable. Participants were used to parents telling them what they thought and felt; this appeared to be the norm - a cultural rule - and so the lack of advice and guidance, on this occasion, seemed to disorient them.

Values, beliefs and norms which appeared to have their own intrinsic logic had been transmitted to the participants from their parents and such internalised values contributed to the participants' attitudes towards HE participation. This was based on the expectation that their family would suffer should they participate, both financially and socially because it might lead the participants to abandon family norms and values and would lead to debt. The participants felt an obligation towards their family's wellbeing because family was viewed as a collective responsibility, whereas participating in HE was an individual endeavour. HE participation was seen as having both financial and social implications. Bourdieu (1998) refers to language that families use that see it as an active agent, that is capable of thought, feeling and action and is a place of trusting and giving. A sense of family solidarity seems to have been inculcated in the majority of the participants and this has influenced and constituted elements of their habitus, both in an individual sense and collectively within the family.

For the majority of the participants, a degree of interpersonal proximity was evident as they lived and socialised in the same place and had developed similar dispositions and outlooks to their peers. Although the participants lived in socially deprived areas, they were attached to their locality and felt that the networks they had fostered within Northtown were much more likely to help them to succeed. These local networks could help them to secure employment locally, something that was 
championed by parents. The majority of participants seemed ill prepared to seek out experiences that they believed might lead to them leaving their locality. They felt comfortable living, socialising and finding work with a network of people with whom they shared the same values, attitudes, behaviours and dispositions.

It appeared that, for the participants, social capital was embedded within their family networks. The relationships that they had forged were much more likely to have value in the long- run than participation in HE. There was clear evidence of mutual support between parents and participants with any connections made by the participants, generally being the result of their parents' social network of connections that were mobilised on the behalf of their children. Participants listened to and valued what parents had to say so there was a common understanding and a mutual respect that was conceptualised in a set of practices that manoeuvred the participants away from HE participation and towards the world of work. What was constructed as a personal decision was actually influenced by discourses within their families, not only in terms of what was and was not said, but also in terms of where and to whom the participants were directed by their parents (Coleman, 1994; Putnam, 2000; Heath, Fuller and Johnston, 2010). The participants had collectively developed a sense of what was, and what was not, for the likes of them (Bourdieu, 1984).

It was evident that bonding social capital, which refers to specific forms of reciprocation associated with homogenous groups, was readily available. Participants and their parents appeared to possess the same values of solidarity, support and mutual reinforcement. The relationships they had with parents, and with others within their parents' wider social networks, helped the participants to 'get by' (Putnam 2000). It appeared that any parental social capital that existed was passed on to the participants by their parents. Bonding social capital constitutes a "... kind of sociological superglue..." (Putnam, 2000, p.23) that creates strong loyalties and ties 
within groups (immediate family, close friends and neighbours) (Putnam, 2000). Various pedagogic processes seemed to take place that influenced the participants' attitudes and beliefs about HE participation. It was the pedagogic authority of the parents, in the eyes of their children, which allowed the informal learning (pedagogic action) that took place to be viewed as legitimate. It may be that their pedagogic ethos predisposed them towards work rather than HE with an assumption that education is only of value if it translates positively into the labour market (Bourdieu, 1973). The combination of the participants' parents not being able to tell them a great deal about $\mathrm{HE}$, in conjunction with the championing of employment, helped shape the participants' habitus and steer them away from HE participation and towards the world of work. The habitus of the participants, which is shaped by early life experiences such as those within the family was embodied and it influenced the way they acted, what they said and did, thought and felt (Bourdieu, 1977). It predisposed the participants to see employment as more likely to bestow social capital by allowing them to develop important, fruitful relationships that could be of benefit, both immediately and in the future (Coleman, 1990; 1994). Without them consciously planning the way in which they did things, such practices appeared to have their own intrinsic logic and therefore seemed rational and made sense to the participants (Bourdieu, 1998).

Interestingly, there was no evidence of bridging social capital which was described by Putnam, (2000) as having the potential to facilitate social mobility. The friendships generated by the participants and their parents were localised, they did not appear to have any distance ties that they could call up on.

\section{Conclusion: Lessons Learned}

This research has enabled a number of lessons to be learned about the direct and indirect influence of parents on HE participation decisions. Firstly, it extends our understanding of how parents can influence values, cultural rules and the HE 
participation decision making of a group of suitably qualified young adults. Whilst other studies have indicated that parental influence is important, this research has found out more about the way this works and how parents influence their children's decisions, both directly and indirectly. This study illustrates how objective social structures such as the family can influence values, cultural rules and decision making. The participants' values appear to have been shaped and moulded by their parents and as a result, the values they held dear and the behaviours that they deemed to be acceptable. They were responding to cultural rules that dictated how they should respond to their parents.

Secondly, this article has demonstrated that the majority of participants had strong affective bonds with their parents and that specific dispositions had been formed that endowed a sense of solidarity in both. The majority of participants had developed common patterns of reaction, what Bourdieu called a 'family feeling', that they shared in relation to parental attitudes to participation in HE (Bourdieu, 1998).

Thirdly, this research has enabled more to be known about the support offered by parents. In spite of their apparent initial support, parents appeared to quickly exhibit collective expectations and socially inculcated beliefs (Bourdieu, 1998) pertaining to employment, once the participants made it known that they did not intend to participate. Consequently, it has enabled more to be learnt about the strategies devised by the participants. Such strategies were focused on making money and finding a job that was much more likely to imbue them with the all-important economic capital that they sought. The socialisation that took place in the family encouraged participants to believe that employment was the right thing to do. 
Parents also directed their children towards networks that could help them to gain local employment. Social capital was bonding in nature and appeared to reproduce inequalities that were already in existence. The participants were unlikely to leave their socially deprived, working class locality, and they were not going to participate in HE. Had parents participated in HE themselves, then social capital that was bridging and linking in nature would have been available to them. This could have: widened the social networks that were open to them; allowed them to make use of people outside of their community and potentially mobilise more distant ties and friendships. This would have given them the opportunity to leverage resources that were more far reaching than those available more locally. This could have led to them making different participation choices (Putnam, 2000). Without them consciously planning the way in which they did things, practices which appeared to have their own built-in and intrinsic logic steered them towards employment. Such decisions seemed rational, they made sense to the participants and they appeared to be influenced significantly by their parents. HE participation was seen as a gamble, and although it may well have led to them gaining more economic capital in the long run, they were not prepared to take a chance (Bailey, 2018). Their future was the world of work. They considered what realistic futures were, for them, because they had internalised the objective chances that they faced (Bourdieu and Passeron, 1990).

Finally, this study has enabled more to be learned about how the participants and their parents could be better supported. It seems that parents and children need to get a better sense of the wider benefits and the point of $\mathrm{HE}$ and its intrinsic value. Ignoring this and focusing entirely on the extrinsic values has not worked well with participants or their parents because, of course, these cannot be guaranteed, and the 
participants and parents seemed to expect an end result. Sixth forms, FE colleges and HE institutions could therefore do more to emphasis the intrinsic benefit of education.

Whilst I realise that there is no guarantee of parental involvement, there appears to be a need for adult education/lifelong learning which seeks to enhance people's appreciation of the non-vocational dimensions of education. If parents and communities experienced life-enhancing education, they might value it more for their children and be able to articulate this to them. As Osborne, Kearns and Yang (2013) point out when discussing the building of a learning society, whilst national governments have a major role in setting the agenda, it is the regions, cities and communities where the real action takes place. 


\section{References}

Bailey, W. (2018). Individual choices? Attitudes to debt and its influence on HE participation decisions. Widening Participation and Lifelong Learning, 20(1), 39-55. doi: https://doi.org/10.5456/WPLL.20.1.39.

Baker, Z. (2019). Priced out: the renegotiation of aspirations and individualized HE 'choices' in England., International Studies in Sociology of Education, 28 (3-4), 299-325. doi: https://doi.org/10.1080/09620214.2019.1619471.

Ball, S., Reay, M., and David, M. (2002). Ethnic choosing: Minority ethnic students, social class and higher education choice. Race Ethnicity and Education, 5 (4), 333-357. doi: https://doi.org/10.1080/1361332022000030879.

Bourdieu, P. (1973). Cultural Reproduction and Social Reproduction in Knowledge Education and Cultural Change. In R. Brown, (Eds.) Knowledge, Education, and Cultural Change (pp. 71-112). London: Tavistock.

Bourdieu, P. (1977). Outline of a Theory of Practice. Cambridge: Cambridge University Press.

Bourdieu, P. (1984). Distinction. Cambridge: Polity.

Bourdieu, P. (1998). Practical Reason. Cambridge: Polity

Bourdieu, P., \& Passeron, J. (1990). Reproduction in Education, Society and Culture. $\left(2^{\text {nd }}\right.$ ed.). London: Sage Publications Ltd.

Braun, V., \& Clarke V. (2006). Using thematic analysis in psychology. Qualitative Research in Psychology. 3(2), 77-101. doi:

https://doi.org/10.1191/1478088706qp063oa.

Brennan, M (2005). The Importance of Incorporating Local Culture into Community Development EDIS. Gainesville: University of Florida.

British Educational Research Association (2018). Ethical Guidelines for Educational Research. Retrieved from https://www.bera.ac.uk/wpcontent/uploads/2018/06/BERA-Ethical-Guidelines-for-EducationalResearch 4thEdn 2018.pdf?noredirect=1

Brooks, R. (2003). Young People Higher Education Choices: the role of family and friends. British Journal of Sociology of Education, 24(3), 283-297. doi: https://doi.org/10.1080/01425690301896.

Burke, P. (2012). The Right to Higher Education: Beyond Widening Participation. Adingdon: Routledge.

Callender, C. \& Mason, G. (2017). Does student loan debt deter Higher Education participation? New evidence from England. Annals of American Political and Social Science, 671(1), 20-48. doi: http//doi.org/10.1177/0002716217696041.

Coleman, J. (1990). Equality and Achievement in Education. Boulder: Westview Press. Coleman, J. (1994). Foundations of Social Theory. Cambridge MA: Belknap Press. 
Crozier, G., Reay D., \& Clayton J. (2010). The socio-cultural and learning experiences of working-class students in higher education. In M. David (Eds.) Improving Learning by Widening Participation in Higher Education (pp. 62-74). London: Routledge.

Department for Communities and Local Government (2015) The English Indices of Deprivation 2015 Technical report. Retrieved from: https://

www.gov.uk/government/publications/english-indices-of-deprivation-2015-technicalreport

Department for Education (2019) Pupil premium: effective use and accountability Retrieved from: https://www.gov.uk/guidance/pupil-premium-effective-use-andaccountability

Dodgson, R. (2004). Parents and Higher Education in the North East of England: Attitudes, Concerns, Influence and Engagement. Journal of Access Policy and Practice, 2(1), 5-23.

Della Porta, D. \& Keating, M. eds. (2008) Approaches and Methodologies in the Social Sciences. A Pluralist Perspective. Cambridge: Cambridge University Press.

Donnelly, M. (2015). A new approach to researching school effects on higher education participation. British Journal of Sociology of Education, 36(7), 1073-1090. doi: https://doi.org/10.1080/01425692.2014.886942.

Esson, J. \& Ertl, H. (2016). No point worrying? Potential undergraduates, study-related debt, and the financial allure of higher education. Studies in Higher Education, 41(7), 1265-1280. Doi: https://doi.org/10.1080/03075079.2014.968543

Evans, C. \& Donelly, M. (2019). A 'home-international' comparative analysis of widening participation in UK higher education. Higher Education, 77(1), 97-114. doi: https://doi.org/10.1007/s10734-018-0260.

Field, J. (2003). Social Capital. London: Routledge.

Foster, C., \& Higson, H. (2008). Involving the family in higher education: do they really matter? Widening Participation and Lifelong Learning, 10(2), 30-40. doi: https://doi.org/10.5456/WPLL.17.4.67.

Fuller, A., \& Heath, S. (2010) Educational decision-making, social networks and the new widening participation. In M. David (Eds.) Improving Learning by Widening Participation in Higher Education (pp. 132-147).London: Routledge.

Gray, D. (2014). Doing research in the real world. (3 ${ }^{\text {rd }}$ ed.). London: Sage Publications. Heath, S., Fuller, S., \& Johnston, B. (2010). Young people, social capital and networkbased educational decision-making. British Journal of Sociology of Education. 31(4), 395-411. doi: https://doi.org/10.1080/01425692.2010.484918.

Heaslip, V., Hewitt-Taylor, J., Alexander, P.; Ellis-Hill, C., \& Seibert-Santos, C. (2015). What factors influence Fair Access students to consider university and what do they look for? Widening Participation \& Lifelong Learning. 17(4), 67-88. doi: https://doi.org/10.5456/WPLL.17.4.67. 
Hegna, K., \& Smette, I. (2017). Parental influence in educational decisions: young people's perspectives, British Journal of Sociology of Education, 38(8) 1111-1124. doi: http://dx.doi.org/10.1080/01425692.2016.1245130.

Jones, S. (2016). Expressions of students' debt aversion and tolerance academically able young people in low-participation English schools. British Educational Research Journal 42(2) 277-293. doi: https://doi.org/10.1002/berj.3209;

Koshey, P., Dockery, A., \& Seymour, R. (2019). Parental expectations for young people's participation in higher education in Australia. Studies in Higher Education, 44(2) 302-317. doi: https://doi.org/10.1080/03075079.2017.1363730.

Kvale, S. (2007) Doing interviews. London: Sage.

Merriam, S. 2009. Qualitative research: A guide to design and implementation (2nd ed.). San Francisco: Jossey-Bass.

Mangan, J., Hughes, A., Davies, P., \& Slack, K. (2010). Fair access, achievement and geography: explaining the association between social class and students' choice of university. Studies in Higher Education, 35(3), 335-350. doi:

https://doi.org/10.1080/03075070903131610.

Office for Students (2019). What is Polar? Retrieved from http:// www.officeforstudents.org.uk/data-and-analysis/polar-participation-of-local-areas/ [Accessed: 1 March 2019]

Osborne, M., Kearns, P., \& Yang, J. (2013). Learning cities: developing inclusive, prosperous and sustainable urban communities'. International Review of Education 59(4), pp. 409-423. doi:10.1007/s11159-013-9384-y

Ponelis , S. (2015). Using Interpretive qualitative studies for exploratory research in doctoral studies: A case of information systems research in small and medium enterprises. International Journal of Doctoral Studies, 10(1) 535-550. doi: https://doi.org/10.28945/2339

Putnam, R. (2000). Bowling alone: The collapse and revival of American community. New York: Simon and Schuster.

Reay, D. (2001). Finding or losing yourself? Working class relationships to education, Journal of Education Policy, 16(4), 333-346. doi:

https://doi.org/10.1080/02680930117164.

Scanlan, M., Powell, F., Leahy, P., Jenkinson, H., \& Byrne, O. (2019). No one in our family ever went to college': Parents' orientations towards their children's postsecondary education and future occupations, International Journal of Education Research, 93(1) 13-22. doi: http://dx.doi.org/10.1016/j.ijer.2018.09.005

Schram, T. (2006). Conceptualising and Proposing Qualitative Research. (2 ${ }^{\text {nd }}$ ed.). Upper Saddle River: Pearson Education.

Shaw, E. (1999). A guide to the qualitative research process: Evidence from a small firm study. Qualitative Market Research: An International Journal, 2(2), 59-70. doi: https://doi.org/10.1108/13522759910269973. 
Thomas, G. (2011). The case: generalisation, theory and phronesis in case study. Oxford Review of Education, 37(1), 21-35. doi:

http//:doi.org/10.1080/03054985.2010.521622.

Thomas, L., \& Quinn, J. (2003). International Insights into Widening Participation: supporting the success of under-represented groups in tertiary education Final report Institute for Access Studies. Stoke-on-Trent: Staffordshire University.

Wilks, J., \& Wilson, K. (2012). Going to uni: Access and participation in university for students from backgrounds of disadvantage. Journal of Higher Education Policy and Management, 34(1), 79-90. doi: doi.org/10.1080/1360080X.2012.642335.

Yin, R. (2014). Case study research: design and methods. (5th ed.). Thousands Oaks: Sage. 